My Brilliant Friends

GENDER AND CULTURE SERIES 


\section{GENDER AND CULTURE}

A Series of Columbia University Press

Nancy K. Miller and Victoria Rosner, Series Editors

Carolyn G. Heilbrun (1926-2003) and Nancy K. Miller, Founding Editors

For a complete list of books in the series see page 223 


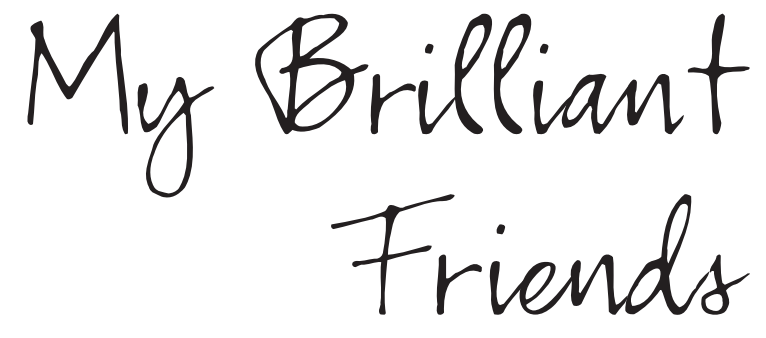

\author{
OUR LIVES \\ IN FEMINISM
}

Nancy K. Miller 
Columbia University Press

Publishers Since 1893

New York Chichester, West Sussex

cup.columbia.edu

Copyright @ 2019 Columbia University Press

All rights reserved

Library of Congress Cataloging-in-Publication Data

Names: Miller, Nancy K., 1941- author.

Title: My brilliant friends : our lives in feminism / Nancy K. Miller.

Description: New York : Columbia University Press, [2018] | Includes bibliographical references.

Identifiers: LCCN 2018022549 (print) | LCCN 2018026082 (e-book) | ISBN 9780231548946 (e-book) | ISBN 9780231190541 (cloth : alk. paper)

Subjects: LCSH: Miller, Nancy K., 1941- | Feminism-United States. | Female friendship-United States.

Classification: LCC HQ1421 (e-book) | LCC HQ1421 .M55 2018 (print) | DDC 305.420973-dc23

LC record available at https://lccn.loc.gov/2018022549

Columbia University Press books are printed on permanent and durable acid-free paper.

Printed in the United States of America

Cover and interior illustrations by Jojo Karlin

Cover and book design: Lisa Hamm 
For Suran Gubar

$\mathscr{\sigma}$ 
